in a paper by C. Sykes and $H$. Wilkinson. The work of Bragg and Williams which attributed the transformation to a change from disorder to order in the lattice is now generally accepted. The present paper provides data which confirm this view, and represents a most valuable contribution to our knowledge of this and similar changes in other metallic alloys.

The academic interest and the practical importance of the volume changes which occur during the hardening of a dental amalgam provide ample justification for two papers by Dr. Marie L. V. Gayler on the constitution of the alloys of silver, tin and mercury and on dental amalgams. The author concludes that the changes taking place on the setting of such an amalgam are to be attributed to complex reactions which probably do not proceed to completion and which may be briefly summed up as :

$$
\begin{aligned}
& \text { (1) } \operatorname{Ag}_{3} \mathrm{Sn}+\mathrm{Hg} \rightarrow \beta_{1}+\gamma_{2} \\
& \text { (2) } \beta_{1}+\gamma_{2} \rightarrow \beta_{1}+\gamma_{1}+\gamma_{2} .
\end{aligned}
$$

No explanation for the marked contraction or expansion which occurs is obtainable from $\mathrm{X}$-ray analysis, but the former is ascribed to the formation of a solid solution of mercury in $\mathrm{Ag}_{3} \mathrm{Sn}$.

In view of the enormous amount of galvanized iron and steel now being used, a critical paper by L. Kenworthy on the methods of testing zinc coatings will arouse wide interest. The value of such protective coatings on iron and steel depends on the average weight, the uniformity, structure and porosity, and under these four headings the various methods which are actually in use, or which have been proposed, are described, together with their respective advan- tages and limitations, and, in certain cases, with suggested modifications.

The determination of alumina in metallic aluminium is a matter of very great difficulty, and a paper by G. B. Brooke and A. G. Waddington makes a substantial contribution in this difficult field of metallurgical analysis. A method is described which has proved superior to any yet proposed for determining alumina in granulated aluminium dross. The complete separation of the metal by volatilization as the chloride in pure hydrogen chloride and subsequent conversion to oxide allows the metallic content to be accurately determined.

It was observed by Hopkinson in 1905 that stresses greatly exceeding the normally accepted values of the tensile strength could be applied to iron and copper wire for very short intervals of time without rupture, and this is now generally believed to hold for all the more common engineering materials. D. W. Ginns describes apparatus in which samples of metals have been broken in 0.005 sec., the yield point being attained in 0.001 sec. It is shown that when compared with ordinary tensile test values the yield point is increased very considerably, at times by more than 100 per cent, that the maximum stress is raised, but to a smaller extent, while the ductility remains more or less unchanged. It is a curious feature of many of these ultra-rapid tests that the yield point and maximum stress coincided, even in metals of high ductility. As a sample of the type of results obtained, the following may be quoted for a steel containing 0.15 per cent carbon. The tensile strength broken at ordinary rates was about 32 tons per square inch, which was raised to 37 tons in the high-speed tests. The corresponding values for the yield point were $22 \cdot 3$ tons per square inch and 37 tons per square inch.

F. C. T.

\title{
The California Sardine and its Fishery
}

$\mathrm{T}$ HE California sardine (Sardinops corrulea) is caught by small motor-boats using purse-seines and round-haul nets with large bunts, called 'lamparas'. The fishery takes place in autumn and winter. The California State Fisheries Laboratory has recently added two more papers to the series of studies of this fishery.

The first paper ("Interseasonal and Intraseasonal Changes in the Size of the California Sardine (Sardinops coerulea)". By Frances N. Clark. Contribution No. 150 from the California State Fisheries Laboratory) deals with the results of the biometrical investigations which have been carried on by the staff of the State Fisheries Laboratory during the last sixteen years. The autumn fishery is of adolescent fish which will spawn for the first time in the following spring, and of the three preceding year groups. In the winter fishery these young fishes continue to be caught, but the bulk of the catch is made up of fishes in their fifth to tenth spawning seasons.

Unusually successful year classes occur at irregular intervals : the study of their effect upon the length frequency polygons of the autumn fishery indicates that the adolescent fishes form a higher proportion of the catches in the southern part of the area (San
Pedro-San Diego) than farther north off Monterey and San Francisco. These large year classes may be detected in the winter fisheries for six or more seasons. The author points out that the autumn fishery draws upon three or four year groups only, as against the eight or ten year groups present during the winter fishing. From the fact that the large year groups of 1929-30 and 1933-34 lost their dominance in the catches more rapidly than the year groups of 1919-20, 1922-23 and 1925-26, the conclusion is drawn that there is a considerable over-fishing of the young fish, and that a serious reduction of the sardine population must be the result.

The seasonal changes in size which occur suggest that the young fishes are to be found off the southern coast of California, and that as they grow older they tend to move farther north after each spring's spawning, so that the oldest fishes inhabit the most northerly part of the range. These old fishes move southward to the spawning grounds.

The fishing grounds of the Californian sardine boats are briefly reviewed in a separate paper ("Fishing Localities for the California Sardine, Sardinops carulea, 1928-1936". By Frances N. Clark. Contribution No. 158 from the California State Fisheries 
Laboratory). In Central California practically no catches are made outside the 100-fathom line. Off Monterey, where the continental shelf is narrow, 81 per cent of the catch of sardines is taken within five miles of the coast. The shelf is wider off San Francisco, and correspondingly more catches are made at greater distances from the shore. In southern California, where the 100 -fathom line is close to the shore, the fish appear to be concentrated along the steep slope, which drops rapidly to 500 fathoms.

\section{Lubrication and Lubricants*}

\section{INDUSTRIAL ApPLICATIONS}

The third group of papers is concerned with industrial applications of lubricants. Catterall and Maitland survey the use of grease in a number of diverse applications, and several papers reveal the extent to which this form of lubricant is being used. Although, as mentioned by Cooper, lubrication by an oil mist would be ideal for ball, roller and needle bearings, they are most commonly lubricated with grease, because grease remains in the housing and affords protection against dust and moisture, which would lead to abrasion and pitting of the accurate surfaces. Cooper, Richardson and Kjerrman all emphasize the undesirability of overfilling the hous. ings, on account of churning, and the care required in choosing greases, advocating an actual running test. Hanocq deals with the friction of ball and roller bearings.

Water-grease emulsions are used in drawing steel tubes (Catterall and Maitland). In the similar operation of cold pressing sheet steel, high pressures are encountered, and Arrowsmith reviews the desirable qualities of the lubricant, film strength, appropriate friction, ease of spreading and of removal, etc.; a fatty oil emulsion containing chalk powder is generally used. High pressures also occur in wire-drawing, and Goodacre states that the lubricant used in dry drawing is a dry sodium soap, in conjunction with some calcium hydroxide remaining after neutralizing the acid used in cleaning. In wet drawing one of the essentials is the formation of a very thin coat of copper or tin on the surface of the metal; the bath usually contains a fatty lubricant and soap, and must contain sulphuric acid. Thompson considers that the friction in the die is of the boundary type, and investigates a number of soaps and liquid lubricants at various temperatures.

Miller contributes a useful review of extreme pressure lubricants as regards composition and the behaviour in various testing machines, and the problems presented by the need for stability, absence of corrosion, etc. ; he refers to future trends and the need for more research, emphasizing the important effect this work on additions to lubricants is having on lubrication generally. Evans gives results of tests in the Almen machine on various oils and greases, and of a number of pure organic compounds in small proportion in mineral oil. Clayton describes the superior behaviour of extreme pressure oils over other gear oils in the 4-ball apparatus, not only in breakdown load and wear, but also in the time to recovery from seizure.

Parker writes on the lubrication of bearings of light mechanisms in which the oils sometimes cannot be renewed during the life of the mechanism. High 'oiliness' has thus been regarded as important, and dolphin and porpoise jaw oils have been used; on *Continued from page 816. account of the oxidation and gumming of these oils, however, mineral oils are now being tried. Stott and Shotter agree that the pivot and cupped-jewel bearing can run well for a time without lubricant, but that oil is necessary for prolonged running at low friction, one of the important functions of the oil being to carry in suspension the iron oxide formed at the contact under the extremely high local pressures.

Hogan, also Nixon and Jackson, describe the difficult problem of lubricating wire ropes; two functions are required of the lubricant : (1) to prevent corrosion; (2) to reduce the friction and prevent seizure of the wires, which make contact with each other at high pressure. Merritt gives much useful information on gear tooth failures and on factors governing the choice of lubricants for gears; Tuplin describes the different methods of applying the lubricant. Blok, in a notable paper, shows, by Bowden's method, the high temperatures reached by gear tooth surfaces under high-pressure running conditions.

\section{Properties and Testing}

The fourth group of papers concerns properties and testing and is of especial interest. In connexion with boundary lubrication, Adam and Kyropoulos review surface phenomena and the function of the adsorbed boundary layer in protecting the metals from cohesive contact. Kyropoulos favours internal molecular mobility rather than elasticity as the explanation of the efficacy of long molecules; also he reasons that the lattice forces of the adsorbing surface ultimately control the lateral packing of the molecules of the boundary layer, thus accounting for the surviving influence of the surface at distances exceeding the range of the original surface forces.

Finch and Zahoorbux describe their work on electron diffraction to show orientation of surface films. Trillat studies adsorption by measuring the rate of change of oil-water interfacial tension by a modification of du Noüy's method. Using oleic acidB.P. paraffin mixtures to provide a scale, the activity of commercial oils can be expressed in equivalent oleic acid content. Examination of an oil before and after passing it over metal balls, through filter paper, etc., shows the adsorption of active molecules at the surfaces. Miss Nottage reports results of static friction tests with fatty acid and wax additions to oils, revealing the effect of atmosphere and adsorbing surface. Fogg describes kinetic friction tests with an oscillating bearing machine; he considers that true boundary friction is obtained below 3 cycles per minute.

Surface finish in relation to the boundary layer is mentioned in a number of papers. Bowden refers to the high temperatures found at sliding contacts; with Leben he shows that sliding is a discontinuous 